\title{
Apparent shear stress and boundary shear distribution in a compound channel flow
}

\author{
K. K. Khatua, K. C. Patra, S. Behera \& P. K. Mohanty \\ Department of Civil Engineering, National Institute of Technology, India
}

\begin{abstract}
The flow structure in any compound channel is a complicated process due to the transfer of momentum between the deep main channel section and the adjoining shallow floodplains. The boundary shear stress distribution in the main channel and floodplain greatly affects the momentum transfer. In the present work, the shear stress distributions across an assumed interface plane originating from the junction between the main channel and flood plain using the Divided Channel Method (DCM) are analyzed and tested for different compound channels and their flow conditions using global data. An improved equation to predict the boundary shear distribution in compound channels for different width ratios is derived that gives better results than other proposed models. Analyses are also done to suitably choose an appropriate interface plane for evaluation of stagedischarge relationship for compound channels having equal roughness in the channel beds and walls. The effectiveness of predicting the stage-discharge relationship using the apparent shear stress equation and boundary shear distribution models are discussed.
\end{abstract}

Keywords: apparent shear, main channel, floodplain, compound channel, discharge estimation, interface planes.

\section{Introduction}

During floods, a part of the river discharge is carried by the main channel and the rest is carried by the floodplains. Momentum transfer between the flow of deep main channel and shallow floodplain takes place making the discharge prediction in compound channel more difficult. In the laboratory the mechanism of momentum transfer between the channel section and floodplain was first investigated and demonstrated by Zheleznyakov [30] and Sellin [24]. 
The traditional discharge predictive methods for compound channels either use the Single-Channel Method (SCM) or the Divided-Channel Method (DCM). The DCM divides a compound section into hydraulically homogeneous sub-sections generally by vertical, inclined or horizontal division lines that lead to an averaged flow velocity for each sub-section (e.g., Chow [4]). These approaches have the advantage of recognizing a particular hydraulic property in the respective compartments. Therefore, this method predicts better overall discharge as compared to SCM (Weber and Menéndez [27], and Patra and Khatua [20]) but it overestimates the flow in main channels and underestimates the flow in the floodplain due to the neglect of lateral momentum transfer.

While using the vertical interface division of DCM, Wormleaton et al. [28] proposed an apparent shear stress ratio, as the useful yardstick in selecting the best interface planes. Holden [6], Lambert and Myers [14], and Patra and Kar [10] also proposed zero shear interface plains that nullify the lateral momentum transfer. The empirical shear stress formulas to calculate the apparent shear at the shear layer between main channel and floodplain (Knight and Hamid [12]) are limited to a particular geometry and are difficult to apply to other data (Knight and Shiono [13]). Based on the published data, Ackers [1] proposed an empirical based correction to the DCM know as Coherence Method (COHM) that is recommended by the UK Environmental Agency Bristol. Shiono and Knight [25] developed a 2-dimensional (SKM) method based on the analytical solution to the depth averaged form of the Navier-Stokes equation. Lambert and Myer [14] developed the weighted divided channel method (WDCM) estimating the discharge capacity for a compound channel.

Toebes and Sooky [33] carried out laboratory experiments and showed that the horizontal interface method would be more realistic than other interface methods. The interaction phenomenon and the discharge assessment for compound sections using DCM were presented by many other researchers as well (e.g., [Bousmar and Zech [3], Knight and Demetriou [11], Knight and Shiono [13], Seckin [23], Patra et al. [19], Kejun Yang et al. [8], Khatua and Patra [10], Abril and Knight [18], Wright and Carstens [29], Yen and Overton [29], Huttof et.al. [7] etc. Failure of most subdivision methods are due to the improper accounting of the complicated interaction between the main channel and floodplain flows, more particularly for channels having wide floodplains. The present study is aimed at understanding the general nature of the interaction between the main channel and the floodplain flows. An attempt has been made to study the information on boundary shear distribution basing on which models on momentum transfer and stage-discharge relationship of compound channels are developed.

\section{Experimental analyses}

In the present work, a compound channel is fabricated using Perspex sheets inside a tilting flume in the Hydraulic Engineering Laboratory of the Civil Engineering Department, National Institute of Technology, Rourkela, India. The compound channel is symmetrical about the centerline of main channel making 
the total width of the compound section as $440 \mathrm{~mm}$ (Figure 1). The main channel is rectangular in cross section having $120 \mathrm{~mm}$ width and $120 \mathrm{~mm}$ at bank full depth. Longitudinal bed slope of the channel is taken as 0.0019 . The roughness of the floodplain and main channel are identical. From the experimental runs in the channel, the bed roughness coefficient (Manning $n$ ) is estimated to be 0.01 . A re-circulating system of water supply is established with pumping of water from an underground sump to an overhead tank from where water flow under gravity to the experimental channel through stilling chamber and baffle wall. A transition zone between stilling tank and the channel helps to reduce the turbulence of the flowing water. An adjustable tailgate at the downstream end of the flume is used to achieve uniform flow over the test reach in the channel for a given discharge. Water from the channel is collected in a volumetric tank that helps to measure the discharge rate. From the volumetric tank water runs back to the underground sump.

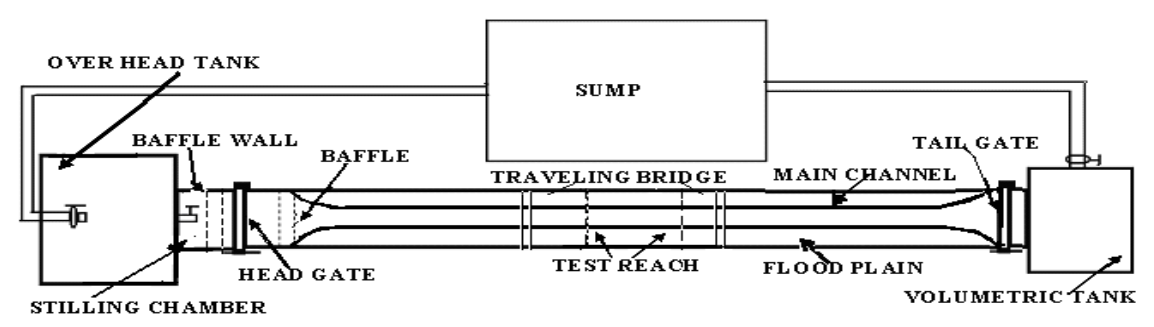

Figure 1: Plan view of experimental set up of the compound channel.

The measuring devices consist of a point gauge mounted on a traversing mechanism to measure flow depths with least count of $0.1 \mathrm{~mm}$. Point velocities are measured at a number of locations across the channel section using a 16-Mhz Micro ADV (Acoustic Doppler Velocity-meter) having accuracy of $1 \%$ of the measured range. A guide rail is provided at the top of the experimental flume on which a traveling bridge is moved in the longitudinal direction of the entire channel. Readings from the micro-ADV were recorded in a computer. As the $\mathrm{ADV}$ (down probe) is unable to read the data up to $50 \mathrm{~mm}$ from free surface, a micro-Pitot tube of $4 \mathrm{~mm}$ external diameter in conjunction with suitable inclined manometer is used to measure velocity at other points in the flow-grid. The Pitot tube is physically rotated with respect to the main stream direction till it records the maximum deflection of the manometer reading. A flow direction finder having a least count of $0.1^{\circ}$ is used to get the direction of maximum velocity with respect to the longitudinal flow direction. The angle of limb of Pitot tube with longitudinal direction of the channel is noted by the circular scale and pointer arrangement attached to the flow direction meter.

A total 21 numbers of stage-discharge data for both in-bank and over-bank flow conditions are observed at the test reach. Out of the 10 over-bank stagedischarge data, detailed velocity measurements for 5 stages are recorded at 


\begin{tabular}{|c|c|c|c|c|c|c|c|c|c|c|}
\hline 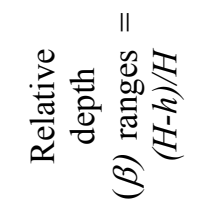 & $\stackrel{\theta}{\ominus}$ & $\begin{array}{l}\bar{b} \\
+ \\
0 \\
1 \\
\infty \\
= \\
\\
0\end{array}$ & $\begin{array}{c}8 \\
0 \\
+ \\
0 \\
1 \\
0 \\
0 \\
0 \\
0\end{array}$ & 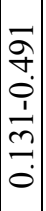 & $\mid$\begin{tabular}{c}
0 \\
0 \\
$n$ \\
0 \\
1 \\
0 \\
0 \\
\hdashline \\
0
\end{tabular} & $\begin{array}{l}8 \\
0 \\
+ \\
0 \\
1 \\
0 \\
0 \\
0\end{array}$ & $\begin{array}{l}\stackrel{9}{f} \\
\dot{J} \\
\dot{1} \\
\dot{J} \\
\dot{J} \\
0 \\
0\end{array}$ & $\begin{array}{l}8 \\
8 \\
n \\
0 \\
1 \\
0 \\
0 \\
0 \\
0\end{array}$ & $\begin{array}{l}\text { oे } \\
\dot{+} \\
\dot{1} \\
\dot{0} \\
0 \\
0 \\
0\end{array}$ & $\begin{array}{l}\text { Jे } \\
+ \\
0 \\
0 \\
0 \\
0 \\
0 \\
0 \\
0\end{array}$ \\
\hline 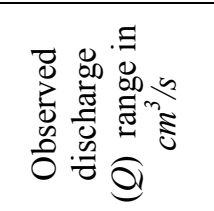 & (2) & 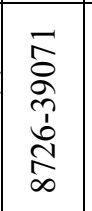 & 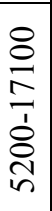 & 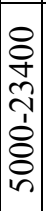 & 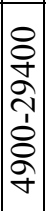 & 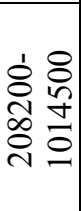 & $\begin{array}{ll}\dot{1} & 8 \\
0 & \stackrel{+}{0} \\
& \pm \\
& \Xi\end{array}$ & $\begin{array}{ll}1 & 8 \\
8 & 8 \\
& 5 \\
\text { సิ } & \infty\end{array}$ & 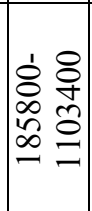 & $\begin{array}{ll}1 & 8 \\
\delta & 8 \\
0 & 2 \\
0 & 2 \\
& 0\end{array}$ \\
\hline 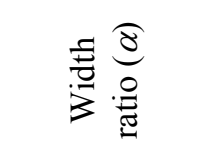 & $\infty$ & $\left|\begin{array}{cc}11 & \hat{\sigma} \\
0 & 0 \\
n & \dot{n}\end{array}\right|$ & $\begin{array}{l}\pi \\
2 \\
m\end{array}$ & $\begin{array}{l}n \\
0 \\
n \\
n\end{array}$ & $\begin{array}{l}\pi \\
\| \\
0 \\
\infty\end{array}$ & $\begin{array}{l}\hat{b} \\
0 \\
\prod_{0}\end{array}$ & 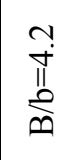 & $\underset{n}{\infty}$ & $\begin{array}{l}\stackrel{0}{+} \\
\| \\
\stackrel{0}{n}\end{array}$ & $\begin{array}{l}\stackrel{\nabla}{+} \\
\stackrel{0}{\infty}\end{array}$ \\
\hline 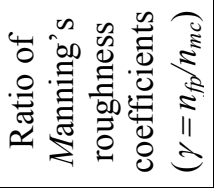 & 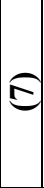 & - & - & -1 & - & - & - & - & - & - \\
\hline 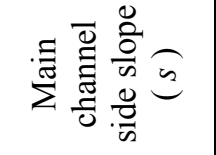 & 6 & 0 & 0 & 0 & 0 & $\stackrel{0}{0}$ & $\stackrel{0}{0}$ & $\stackrel{0}{-}$ & 0 & $\stackrel{\circ}{\sim}$ \\
\hline 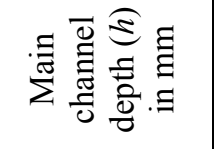 & (6) & ㄱ & 2 & 2 & 2 & $\stackrel{n}{n}$ & $\stackrel{n}{n}$ & $\stackrel{n}{n}$ & $\stackrel{ }{n}$ & $\stackrel{\cap}{n}$ \\
\hline 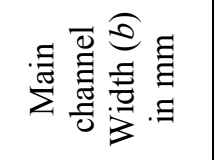 & $\overparen{\Xi}$ & $\stackrel{ }{\text { ㄱ }}$ & ర্ল & 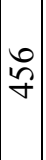 & $\mid \begin{array}{l}\infty \\
0 \\
0\end{array}$ & $\begin{array}{l}8 \\
\stackrel{n}{n}\end{array}$ & $\begin{array}{l}8 \\
\stackrel{n}{n}\end{array}$ & $\stackrel{8}{8}$ & $\begin{array}{l}8 \\
\stackrel{n}{n}\end{array}$ & $\begin{array}{l}8 \\
\stackrel{n}{n}\end{array}$ \\
\hline 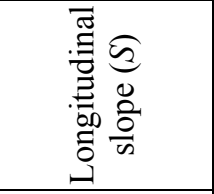 & (2) & $\begin{array}{l}\stackrel{\circ}{\circ} \\
\stackrel{0}{0}\end{array}$ & $\begin{array}{l}\circ \\
\stackrel{2}{8} \\
8 \\
0 \\
0\end{array}$ & $\mid$ & $\mid \begin{array}{l}0 \\
8 \\
8 \\
8 \\
0 \\
0\end{array}$ & $\begin{array}{l} \\
0 \\
x \\
\frac{1}{\Delta} \\
0 \\
\dot{r}\end{array}$ & $\begin{array}{l}1 \\
0 \\
x \\
\\
0 \\
-1\end{array}$ & 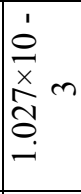 & 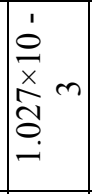 & $\begin{array}{l}1 \\
0 \\
x \\
\\
0 \\
0 \\
-\end{array}$ \\
\hline 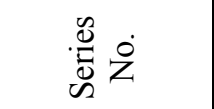 & (2) & 离 & $\overline{0}$ & ชิ & 0 & $\overline{0}$ & ปู & $\widehat{0}$ & $\stackrel{\infty}{\circ}$ & $\stackrel{0}{ }$ \\
\hline 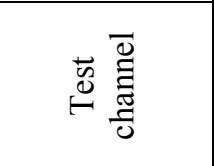 & $y$ & 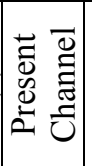 & \multicolumn{3}{|c|}{ 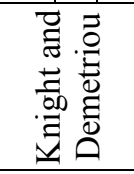 } & \multicolumn{5}{|c|}{ 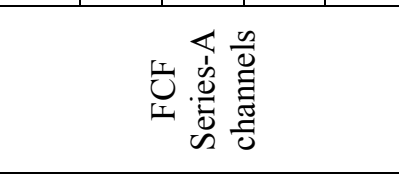 } \\
\hline
\end{tabular}


a number of points at the pre defined grid points. The overall discharge obtained from integrating the longitudinal velocity plot and from volumetric tank collection is found to be within $\pm 3 \%$ of the values. Using the velocity data, the boundary shear on the channel beds and walls are evaluated from a semi log plot of velocity distribution. Boundary shear stresses are also obtained from the manometric readings of the head differences of Preston tube techniques using Patel's [17] relationship. Error adjustments to the shear value are done by comparing the corresponding shear values obtained from the energy gradient approach. The results so obtained by the two methods are found to be consistently within $\pm 3 \%$ values. Summary of the discharges and percentage of boundary shear in the floodplain $\left(\% S_{f p}\right)$ for different relative depths $(\beta)$ observed from the experimental runs are given in Table 1.

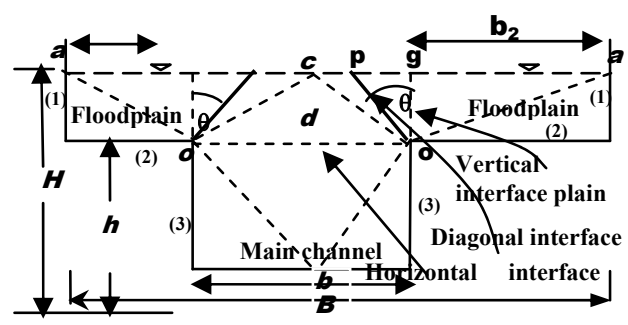

Figure 2: Interface planes dividing a compound section into subsections.

\section{Methodology}

\subsection{Shear force on the assumed interface planes}

In Figure 2, the vertical, horizontal, and diagonal plains of separation of the compound channel are represented by the interface lengths o-g, o-o, and o-c respectively. Various boundary elements comprising the wetted parameters are labeled as (1), (2), (3) and (4). Label (1) denotes the vertical wall(s) of floodplain of length $[2(H-h)]$, where $H=$ total depth of flow from main channel bed, $h=$ depth of main channel. Label (2) denotes floodplain beds of length $(B-b)$, where $B=$ total width of compound channel, and $\mathrm{b}=$ width or bed of main channel represented by label (4) Label (3) denotes the two main channel walls of length $(2 h)$. Experimental shear stress distributions at each point of the wetted perimeter are numerically integrated over the respective sub-lengths of each boundary element (1), (2), (3), and (4) to obtain the respective boundary shear force per unit length for each element. Sum of the boundary shear forces for all the beds and walls of the compound channel is used as a divisor to calculate the shear force percentages carried by the boundary elements (1) - (4). Percentage of shear force carried by floodplains comprising elements (1) and (2) is represented as $\% S_{f p}$ and for the main channel comprising elements (3) and (4) is represented as $\% S_{m c}$. Following Knight and Demetriou [11], Knight and Hamed [12] proposed an equation for $\% S f p$ for a compound channel section as 


$$
\% S_{f p}=48(\alpha-0.8)^{0.289}(2 \beta)^{m}
$$

Equation (1) is applicable for the channels having equal surface roughness in the floodplain and main channel. For non-homogeneous roughness channels the equation is improved as

$$
\% S_{f p}=48(\alpha-0.8)^{0.289}(2 \beta)^{m}\{1+1.02 \sqrt{\beta} \log \gamma\}
$$

in which $\alpha=$ width ratio $=B / b, \beta=$ relative depth $=(H-h) / H, \gamma=$ the ratio of Manning's $n$ of the floodplain to that for the main channel, $h=$ bank full depth and $H=$ total depth of flow. The exponent $m$ can be evaluated from the relation

$$
m=1 /\left[0.75 e^{0.38 \alpha}\right]
$$

For homogeneous roughness section $(\gamma=1)$, equation (2) reduces to the form of Knight and Hamed [12] i.e. equation (1). Due to complexity of the empirical equations proposed by the previous investigators, a regression analysis is made by Khatua and Patra [10] and equation for $\% S_{f p}$ is proposed as

$$
\% S_{f p}=1.23 \beta^{0.1833}(38 \operatorname{Ln} \alpha+3.6262)\{1+1.02 \sqrt{\beta} \log \gamma\}
$$

Once the shear force carried by the floodplain is known from equation (4), the momentum transfer in terms of apparent shear force acting on the imaginary interface of the compound section can be calculated. The analysis of momentum transfer helps in predicting the stage-discharge relationship of a compound channel, which is discussed in the later part of the paper. For any regular prismatic channel under uniform flow conditions, the sum of boundary shear forces acting on the main channel wall and bed, along with an "apparent shear force" acting on the interface plane originating from the main channelfloodplain junction must be equal to the resolved weight force along the main channel. Using the concept, Patra and Kar (2000) derived the percentage of shear force $A S F_{i p}$ acting at the interface plane as

$$
\% A S F_{i p}=100 \frac{A_{m c}}{A}-\left\{100-\% S_{f p}\right\}
$$

in which $\% \mathrm{ASF}_{\text {ip }}=$ percentage of shear force in the interface plane. Having computed $\% S_{f p}$ using equation (2) or (4), it is easy to evaluate equation (7) for the assumed interface plane. From experiments it is seen that apparent shear stress is higher than the bed-shear stress at low floodplain depths and reduces gradually as over-bank flow depth increases (Rajaratnam and Ahmadi [22], Myers and Elsawy [16], Knight and Demetriou [11], Patra and Khatua [20]). A smaller value of apparent shear stress renders the interface plane more suitable, but a large negative value of apparent shear stress at higher depths makes the interface plane unsuitable for separating the channel into hydraulically homogeneous sub-sections for calculating discharge of compound channels by Divided Channel Method (DCM). The momentum transfer from the main channel to flood-plain is considered as positive percentages of apparent shear and that from flood-plain to main channel is taken as negative. 


\subsection{Shear force along assumed interface planes in terms of angle $\theta$}

Evaluation of apparent shear force at the imaginary interface is helpful for DCM to choose appropriate sub-division lines for separating a compound channel into sub-sections for discharge assessment. Based on the previous works, a general expression for momentum transfer across any interface plane in terms of the angle $(\theta)$ made with the vertical line is derived. Consider an arbitrary interface (op), lying between extreme interfaces (oa) and (oe) which make an angle $\theta$ to vertical line at the junctions (Figure 2). The convention, used for $\theta$ is $0^{\circ}$ for vertical interface $(\mathrm{og})$, positive if the interface lies in the main channel and negative, if the interface lies at the floodplain side. Two situations of locating interface plains can arise.

First, when interface (op) lies between (oa) to (oc) the ranges of angle $\theta$ can be defined as $\tan \theta \leq \frac{b}{2(H-h)}$ and $\tan (-\theta) \leq \frac{b_{1}}{(H-h)}$ or $\leq \frac{b_{2}}{(H-h)}$. The area of main channel for this condition is given as $A_{m c}=b H-(H-h)^{2} \tan \theta$, where $b_{1}$ and $b_{2}$ are the lengths of flood plain bed at both sides measured from vertical interface. For a symmetrical compound channel $b_{1}=b_{2}=(B-b) / 2$. The total area of cross section of channel is $A=b H+(B-b)(H-h)$. Substituting the value of $A_{m c}$ and $A$ in (7) and simplifying, the expression for percentages of apparent shear force in the assumed interface is

$$
\% A S F_{i p}=100 \frac{\left(\delta-\beta^{2} \tan \theta\right)}{\delta\{1+(\alpha-1) \beta\}}-\left(100-\% S_{f p}\right)
$$

where $\delta=$ aspect ratio of the main channel $=b / h, \alpha=$ width ratio and $\beta=$ relative depth which are defined earlier. The second case is when interface op lies between oc to oe, the ranges of angle $\theta$ for this situation can be calculated from the relations given as $\tan \theta \leq \frac{2 h}{b}$ and $\tan \theta \geq \frac{b}{2(H-h)}$. The area of main channel is $A m c=b h+\frac{b^{2}}{4} \tan \theta$ and that for whole compound channel is $A=$ $b H+(B-b)(H-h)$. Substituting the value of $A_{m c}$ in (7) and simplifying we get

$$
\% A S F_{i p}=100\left\{\frac{\delta \cot \theta-4 \beta+4}{4\{1+(\alpha-1) \beta\}}\right\}-\left(100-\% S_{f p}\right)
$$

For any given interfaces the angle $\theta$ is known so the equation (6) and (7) can be directly used to find the apparent shear along any interfaces. 


\section{Results and discussions}

\subsection{Boundary shear distribution results}

It is seen that the magnitude of momentum transfer at an interface plains using equations (6), or (7) depend on the dimensionless parameters like $\alpha, \beta$ and $\% S_{f p}$. At a given over-bank flow depth for any compound river section both the parameters $\alpha$ and $\beta$ are known. The third parameter $\% S_{f p}$ can be calculated using equation (2) of Knight and Hamed [12] or by equation (4) of Khatua and Patra [10]. Knight and Hamed [12] have shown the adequacy of equation (2) for the compound channels having width ratio $\alpha$ up to 4 . However, Khatua and Patra [10] have shown the adequacy of $\alpha$ up to 5.25. Interestingly, it is found that when both the equations are tested for FCF data having $\alpha=6.67$, significant error in $\% S_{f p}$ is estimated [around $90 \%$ by equation (2) and $71 \%$ by equation (4)]. Figure 3, illustrates the results for FCF data obtained using equations (2) and (4) and its comparison with the observed values. The errors are found to increase with increase in the value of $\alpha$ (width ratio) as well as with the increase of $\beta$ (relative depth). Furthermore, equation (2) and (4) estimates unrealistic value of $\% S_{f p}$, that is $\% S_{f p}>100 \%$ for a compound channel of $\alpha>10$. Wide floodplains $(\alpha>10)$ are generally encountered during high floods in natural channels and it is essential to estimate boundary shear stress distribution for such channels.

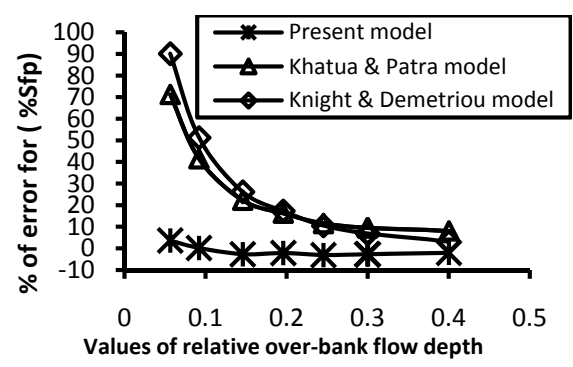

Figure 3: $\quad$ Variation of $\%$ error for calculating $\% S_{f p}$ with $\beta$ for FCF data.

For a better understanding the boundary shear stress distribution, the authors have studied the five series of FCF phase A channels $[\alpha=2.6,4.0,4.2,4.4$, and 6.67], three series of compound channel data $[\alpha=2,3$, and 4] of Knight and Demetriou [11] along with the data of present compound channel [ $\alpha=3.67]$. These compound channels have homogeneous roughness both in the main channel and floodplain sub-sections. Details of the experimental arrangements relating to phase A to $\mathrm{C}$ of the FCF work are obtained from Greenhill and Sellin [5]. Experiments for other three channels are described by Knight and Demetriou [11]. On the basis of total 62 overbank flow depth from nine different 


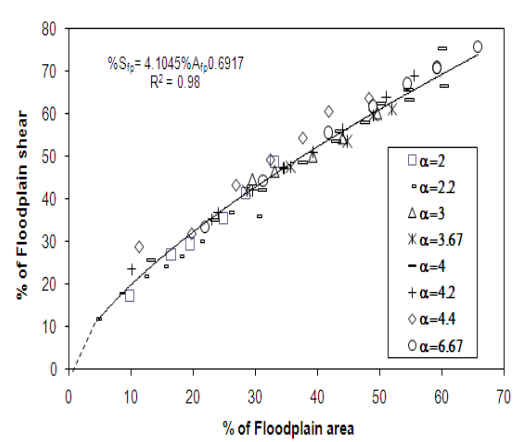

Figure 4: Variation between $\% S_{f p}$ and corresponding flow area $\% A_{f p}$.

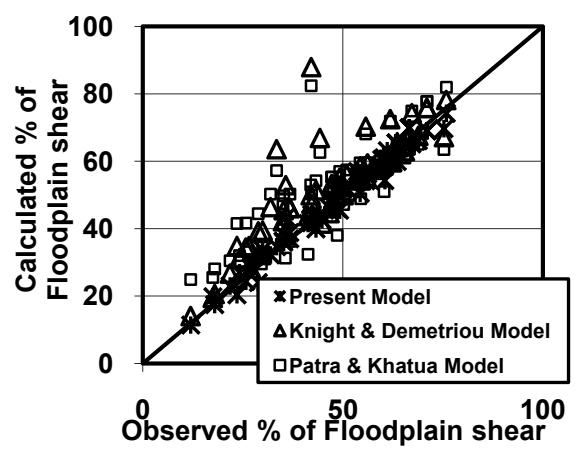

Figure 5: Variation of observed and modeled value of $\% S_{f p}$.

types of compound channels with width ratios $\alpha$ ranging from 2.0 to 6.67 and relative depths $\beta$ ranging from 0.1 to 0.5 , the authors have tried to plot the variation of percentages of floodplain area $\% A_{f p}$ verses $\% S_{f p}$ in Figure 4 given as.

$$
\% S_{f p}=4.1045\left(\% A_{f p}\right)^{0.6917}
$$

By substituting $\frac{A_{f p}}{A}=\frac{\beta(\alpha-1)}{1+(\alpha-1) \beta}$ for a rectangular main channel, equation (8)

is rewritten as

$$
\% S_{f p}=4.105\left[\frac{100 \beta(\alpha-1)}{1+\beta(\alpha-1)}\right]^{0.6917}
$$

Now, the equation (9) can be used for the channels having equal surface roughness in the floodplain and main channel. For non-homogeneous channels, equation (9) can further be modified as

$$
\% S_{f p}=4.105\left[\frac{100 \beta(\alpha-1)}{1+\beta(\alpha-1)}\right]^{0.6917}\{1+1.02 \sqrt{\beta} \log \gamma\}
$$

Using the equation (10), the variation between the calculated $\% S_{f p}$ and observed values for all the ten types of compound channels are shown in Fig.5. In the same plot the variation of calculated $\% S_{f p}$ by previous investigators (i.e. equations 2 and 4$)$ are also shown. The plot indicates high correlations $\left(R^{2}=\right.$ 0.98 ) for(10) and $R^{2}=0.68$ and 0.74 respectively using equations (2) and (4).

\subsection{Shear force on the assumed interface planes for an angle $\Theta$}

Further to account for the momentum transfer, the present experimental results are analysed using equation (10) and are plotted in Figure 6. The convention for momentum transfer is positive from the main channel to flood-plain and that from flood-plain to main channel is negative. As can be seen, the apparent shear 


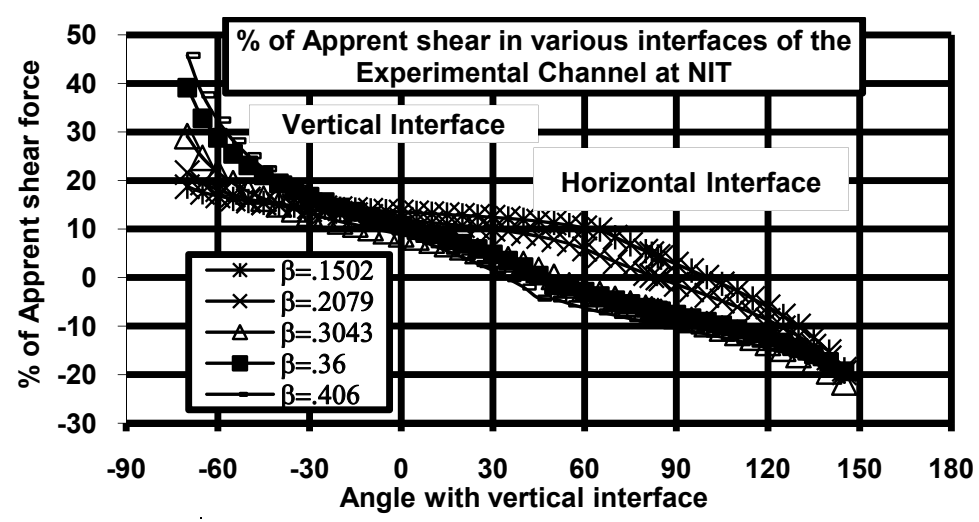

Figure 6: Variation of apparent shear along various interface planes.

in the vertical interfaces is found to be $13.5 \%$ of the total shear for the overbank flow depth of $2.12 \mathrm{~cm}(\beta=0.15)$. It is found that the apparent shear decreases as the flow depth increases and reaches to $9.1 \%$ for a overbank flow depth of 8.21 $\mathrm{cm}(\beta=0.406)$. This shows that apparent shear is higher at low floodplain depths and gradually reduces as depth over floodplain increases. Similar results are also obtained for horizontal and diagonal interface plane for the present channels as well as when global data sets are tested using the concept. The interface plain of zero shear is located near the horizontal interfaces (approximately at $\theta=99^{\circ}$ ) at $\beta=0.15$ and for higher over-bank flow depths, the interface plane of zero shear is observed near a diagonal line of separation (approximately at $\theta=40^{\circ}$ ).

\subsection{Estimating discharge using different approaches}

Let $Q_{c}$ denotes the calculated discharge and $Q_{m}$ the measured discharge. The percentage of error and standard error for each series of experimental runs are computed using the equation given as

$$
\operatorname{Error}(\%)=\frac{\left(Q_{c}-Q_{m}\right)}{Q_{m}} \times 100
$$

Using the vertical, horizontal, diagonal, and other interface planes, the error in discharge estimation for the experimental channel and one channel from the FCF (series A) are plotted in Figures 7(a) and 7(b) respectively.

In DCM, proper selection of the interface plane is required using the value of the apparent shear at the assumed interface plane. If the shear stress at this interface is zero, then there is no momentum transfer across the selected interface and therefore the length of the interface is not included to the wetted perimeter of the main channel or the floodplain for discharge calculation using divided channel method and Manning's equation. However due to the difficulty in locating this plane for all channel geometry and flow depths, investigators either include or exclude the interface lengths in calculating the wetted perimeter for the estimation of discharge. By including this interface length to the wetted 
perimeter of the main channel, a shear drag of magnitude equal to the interface length times the average boundary shear is included. However, in such situations the actual interface shear is not considered as the shear along this interface is not equal to the boundary shear for all depths of flow in the channel. Similarly, by excluding these lengths, a zero shear along these interfaces is assumed.

Single channel method (curve SCM, where the whole compound section is considered as single one) is found to give higher discharge error for lower overbank flow depths and very less error for high over-bank flow depth which is in line with the findings of Seçkin [23]. These also show that at very high overbank depths, the compound channel behaves like a single unit (Bhowmik and Demissie [2]). SCM also gives the maximum point error [e.g. for $\alpha=6.67$ discharge error is more than $45 \%$ (Figures $7 \mathrm{~b}$ ). Similarly, VDM-II (curve Vie) gives better discharge results than VDM-I (curve Vee) which is in line with the findings of Mohaghegh and Kouchakzadeh [15]. VDM-1 (curve Vee) provides higher error for compound channels of wider floodplain (e.g. $\alpha=6.67$ of Figure 7). For all the compound channels studied, the error results from HDM-I (curve Hee) is less than that from HDM-II (i.e curve Hie) which is in line with the findings of Seçkin [23]. It is again observed that HDM-I approach gives better discharge results than the corresponding vertical interface method (VDMI) for low depths of flow over floodplain but gives large discharge error at higher depths. These findings are similar to the results of Mohaghegh and Kouchakzadeh [15]. It is also noticed that, DDM (curve Dee) gives less error (Figure 7) than all the VDM and HDM for all the compound channels studied. This finding follows the results of Wormleaton et al [28]; Knight and Hamed [12], Khatua [9] and Seçkin [23] etc. Both the area method (curve AM) and the variable inclined plain method (curve VI) gives higher standard error for

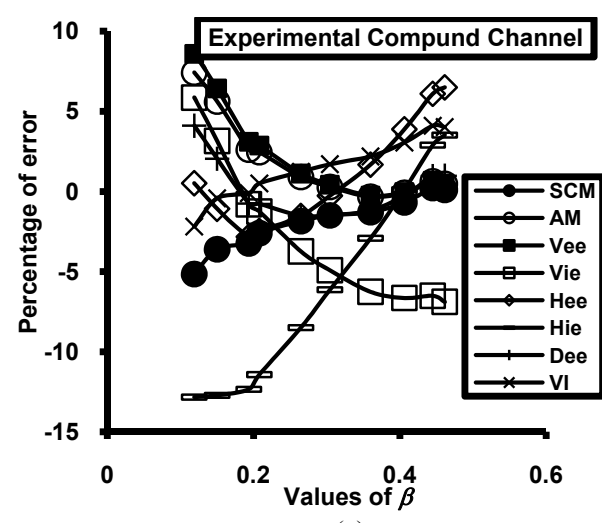

(a)

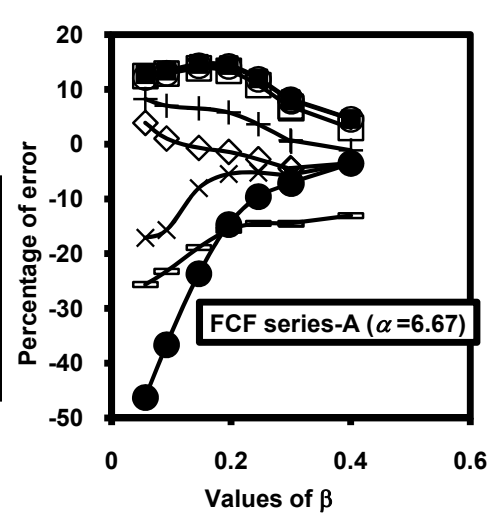

(b)

Figure 7: (a) and (b): Variation of percentage of error discharge with relative depth by various approaches for experimental channel and the FCF channel. [SCM-Single Channel Method, Vee-(VDM-1), Vie-(VDM-1I), Hee(HDM-I), Hie-(HDM-1I), Dee-DDM, Ma-Zero Shear Interface Method (ZSIM), AM-Area Method, VI-Variable Inclined Plain Method]. 
compound channels of wider floodplains (e.g FCF Series-A channels, Figure 7b). Basing on the present analysis, it can be concluded that both HDM-1 and DDM are good approaches. HDM-1 is better for low overbank depth and DDM is better for higher overbank depths.

\section{Conclusions}

The following conclusions can be drawn from the above investigation

* For a compound channel the important parameters affecting the boundary shear distribution are the relative depth $(\beta)$, the width ratio $(\alpha)$, and the relative roughness $(\gamma)$. These three dimensionless parameters are used to form equations to represent the total shear force percentage carried by floodplains. The present formulations for estimating the percentages of shear force carried by floodplain boundary $\% S_{f p}$ has the distinct improvement when compared to the previous investigators in the sense that it is quite adequate for all types of straight compound channel geometry (narrow as well as wide flood plain channels). Equations by the previous investigators give $\% S_{f p}$ more than $100 \%$ when applied to a compound channel of wider floodplains (i.e. width ratio $\alpha>10$ ).

* Using the boundary shear distribution results, the momentum transfer at different interfaces originating from the main channel and floodplain junction for all types of geometry are quantified. The proposed equation provides the estimation of apparent shear stress for any assumed interface in terms of an angle $\theta$ it makes with the vertical line. Furthermore the stage-discharge relationship of a compound channel using divided channel method is decided only after finding the apparent shear stress across the interface planes.

* Basing on the present analysis using DCM, it can be concluded that both HDM-1 and DDM are better than other approaches. HDM-1 is good for low overbank depths and the DDM subdivision is better for higher overbank depths. The adequacy of the developed equation for shear stress distribution along the boundary of compound channels is verified using the data from FCF-A channels.

\section{References}

[1] Ackers P, Hydraulic Design of Two Stage Channels, Proc. of the Inst. of Civil Engineers, Water Maritime and Energy, 96(4) (1992) 247-257.

[2] Bhowmik N.G., Demissie M, Carrying Capacity of Flood Plains, J Hydraul Eng, ASCE ,108(HY3) (1982) 443-453.

[3] Bousmar D, Zech Y, Momentum Transfer for Practical Flow Computation in Compound Channels, J Hydraul Eng, ASCE,125(7) (1999) 696-706.

[4] Chow V.T, Open Channel Hydraulics, McGraw Hill Book Co. Inc., New York, 1959. 
[5] Greenhill R.K., Sellin R.H.J, Development of a Simple Method to Predict Discharge in Compound Meandering Channels. Proc. of the Inst. of Civil Engineers. Water, Maritime and Energy, 101 (1993) 37-44.

[6] Holden, Shear Stress and Discharge in Compound Channels, Thesis presented to the University of the Witwatersrand at Johannesburg for partial fulfillment of the requirement of the degree of M.Sc, 1986.

[7] Huthoff F.P.C, Roos D.C.M, Augustijn S.J.M, Hulscher H, Interacting Divided Channel Method for Compound Channel Flow, J Hydraul Eng, ASCE, 134(8) (2008) 1158-1165.

[8] Kejun Yang, Shuyou Cao, Xingnian Liu, Flow Resistance and Its Prediction Methods in Compound Channels. Springer Verlag, 2007.

[9] Khatua K.K, Interaction of Flow and Estimation of Discharge in Two Stage Meandering Compound Channels. Thesis Presented to the National Institute of Technology, Rourkela, in partial fulfillments of the requirements for the Degree of Doctor of Philosophy, 2008.

[10] Khatua K.K, Patra K.C., Boundary Shear Stress Distribution in Compound Open Channel Flow, J Hydraul Eng, ISH,12(3) (2007) 39-55.

[11] Knight D.W, Demetriou J.D, Floodplain and Main Channel Flow Interaction. J Hydraul Eng., ASCE, 109(8) (1983) 1073-1092.

[12] Knight D.W, Hamed M.E, Boundary Shear in Symmetrical Compound Channels. J of Hydraul Eng, ASCE, 110 (10) 1984 1412-1430.

[13] Knight D.W, Shiono K, River Channel and Floodplain Hydraulics, Floodplain Processes, by Anderson M.G., Walling D E., Paul D, 1996.

[14] Lambert M.F, Myers W.R, Estimating the Discharge Capacity in Straight Compound Channels, Proceedings of the Institute of Civil Enggs, Water, Maritime and Energy, 130 (1998) 84-94.

[15] Mohaghegh A, Kouchakzadeh S, Evaluation of Stage-Discharge Relation in Compound Channels, J Hydrodynamics, 20(1) (2008) 81-87.

[16] Myers W.R.C, Elsawy. Boundary Shear in Channel With Floodplain, J Hydraul Div, ASCE, 100(7) (1975) 933-946.

[17] Patel V.C, Calibration of the Preston tube and limitations on its use in pressure gradients. J Fluid Mech, 23(1) (1965) 185-208.

[18] Patra K. C, Kar S.K, Flow interaction of Meandering River with Flood plains. Journal of Hydraulic Engineering, ASCE, 126(8) (2000) 593-603.

[19] Patra K. C, Kar S.K, Bhattacharya A.K, Flow and Velocity Distribution in Meandering Compound Channels. J Hydraul Eng, ASCE, 130(5) (2004) 398-411.

[20] Patra K.C, Khatua K.K, Selection of Interface Plane in the Assessment of Discharge in Two Stage Meandering and Straight Compound Channels, Proc. Of Inter. Conf. on Fluvial Hydraul, Lisbon, (2006) 379-387.

[21] Prinnos P, Townsend R.D ,Comparison of Methods of Predicting Discharge in Compound Open Channels, Adv. Water Resour ,7(12) (1984)180-187.

[22] Rajaratnam N, Ahmadi R.M, Interaction between Main Channel and Flood Plain Flows. J Hydraul Div, ASCE, 105(HY5) (1979) 573-588. 
[23] Seçkin G, A comparison of one-dimensional methods for estimating discharge capacity of straight compound channels. Canadian J Civil Eng, 31(4) (2004) 619-631.

[24] Sellin R.H.J, A Laboratory Investigation into the Interaction between Flow in the Channel of a River and that of its Flood Plain. La. Houilte Blanche, 7 (1964) 793-801.

[25] Shiono K, Knight, D. W. Turbulent Open Channel Flows with Variable Depth across the Channel Fluid Mech, 222 (1991) 617-646.

[26] Toebes G. H, Sooky A, Hydraulics of Meandering Rivers with Floodplains. J Wtrwy Harbor Div, ASCE, 93(2) (1967) 213-236.

[27] Weber J. F, Menéndez A. N, Performance of Lateral Velocity Distribution Models for Compound Channel Sections, Proc Int. Conf. on Fluvial Hydraul, Balkema, Rotterdam, the Netherlands, (2004) 449-457.

[28] Wormleaton P.R, Allen J, Hadjipanos, P, Discharge Assessment in Compound Channel, J Hyd. Div, ASCE, 108(HY9) (1982) 975-994.

[29] Yen, C.L, Overton D.E, Shape Effects on Resistance in Floodplain Channels, J Hydraul Div, ASCE, 99(1) (1973) 219-238.

[30] Zheleznyakov G.V, Relative deficit of mean velocity of instable river flow: Kinematic effect in river beds with floodplains. Proc. Inter. Conf. IAHR, (1965). 